\title{
The Continuing Education to Include Students with Autism Spectrum Disorder: Looking at Adapted Assessments
}

\author{
Talita Retzlaff ${ }^{1}$, Lucelmo Lacerda ${ }^{2}$, Aldo Sena de Oliveira ${ }^{1,3^{*}}$ \\ ${ }^{1}$ Postgraduate Program in Teaching Natural Sciences and Mathematics at the Regional University of Blumenau (FURB), \\ Blumenau, Brazil \\ ${ }^{2}$ Department of Psychology, Education and Human Sciences Center, Federal University of São Carlos (UFSCar), \\ São Carlos, Brazil \\ ${ }^{3}$ Department of Exact Sciences and Education, Technological, Science and Education Center, Federal University of Santa Catarina \\ (UFSC), Blumenau, Brazil \\ Email: *aldo.sena@ufsc.br
}

How to cite this paper: Retzlaff, T., Lacerda, L., \& de Oliveira, A. S. (2020). The Continuing Education to Include Students with Autism Spectrum Disorder: Looking at Adapted Assessments. Creative Education, $11,1825-1841$

https://doi.org/10.4236/ce.2020.119134

Received: July 19, 2020

Accepted: September 26, 2020

Published: September 29, 2020

Copyright (c) 2020 by author(s) and Scientific Research Publishing Inc. This work is licensed under the Creative Commons Attribution International License (CC BY 4.0).

http://creativecommons.org/licenses/by/4.0/

(c) (i) Open Access

\begin{abstract}
There is an urgent need for the Brazilian school to achieve better conditions for teaching in diversity. The realization of specific pedagogical actions of teaching knowledge, such as continuing education in the perspective of inclusive education, will open the spheres of knowledge to all students, respecting their particularities. The implementation of the necessary actions for the teaching of students with autism, especially within Mathematics Education, an area of majority commitment of this public, passes diametrically through the training and specialization of the teaching staff of a school. Thus, the article aims to present the development and application of a training course, given to teachers of Basic Education, with the theme Autism Spectrum Disorder, in order to investigate the impact of a course of this nature on the accuracy in adapting assessments. It was possible to verify that the course taught by the researcher in fact taught general approaches and specific strategies that help educators in a deliberate and proactive way to design instructions that respond to the variability of students present in their classrooms, and the material developed and used during the training. They represent broad structures that provide guidelines and strategies to make the curriculum accessible to students with the profile according to our model.
\end{abstract}

\section{Keywords}

Autism, Mathematics Education, Adapted Assessment 


\section{Introduction}

The School Census of Basic Education of the National Institute of Educational Studies and Research Anísio Teixeira-INEP 2020, states that the number of students with disabilities, Global Developmental Disorders, or high skills, included in common classes exceeds the 1.3 million mark. This phenomenon invites collective reflection on the concept of education for all, the practices appropriate to the peculiarities of special educational needs (SEN) and the decisions that need to be taken to make the educational practice effective, since what notes that a large part of the educational environments are not prepared to make school inclusion happen in a complete way, that is, so that all inserted students have conditions of access, permanence and learning (Brito \& Costa, 2018).

In this sense, it is possible to recognize the importance of the teacher in the process. The teacher is responsible for mediating knowledge, walking with the student, showing him the way, teaching how to conduct research, enabling the search, promoting a favorable climate for learning, contextualizing the contents with his reality and, above all, making teaching pleasant. To comply with all these premises, it must be inextricably endowed with creativity and differentiated methodologies, which will guarantee the student's training as a citizen (Brito \& Costa, 2018).

The most conclusive studies on Autistic Spectrum Disorder, according to the Center for Disease Control and Prevention (CDC) - an agency of the United States Department of Health and Human Services-point to an approximate prevalence of 1 in 54 births (Maenner et al., 2020), and the number of students with the disorder in common teaching classes has grown exponentially every year (Brasil, 2020).

The Autism Spectrum Disorder (ASD) is defined by a condition characterized by a symptomatic set, characterized by "persistent deficits in communication and social interaction; and restricted and repetitive patterns of behavior, interests and activities" (Lacerda, 2017). The word spectrum is an expression that comes from Physics, denotes a wide radius, and refers to the various levels of impairment, whose diagnostic distinction is categorized between mild, moderate, and severe autism. This means that many people, vastly different, are at different points within the same context.

According to Tibyriçá and D'Antino (2018), with the enactment of Law 12764/12, people with ASD now have Public Policies that guarantee the necessary means for the person with autism to have a dignified life, from medical assistance, security, multiprotection assistance, even punishment with a fine of three to twenty minimum wages to the school manager or competent authority that refuses the enrollment of the student with autism. However, in many cases, the practice is still dissociated from the theory and the student with ASD does not receive due attention in the classroom to be able to develop its full potential.

From a more accurate view, it is possible to understand that the teacher needs to assume his role and make efforts in search of developing specific strategies for 
pedagogical support, that is, forms of structured education or structured intervention paths that make up the construction of these adaptations instructions, activities and materials, through which students with autism can also, at term, accompany the class in the concepts that are being worked on.

In this sense, it is necessary to recognize the difficulty found by the teachers responsible for the regular classes, or generalist teachers, to find materials that deal with this theme and that can contribute to their practice, mainly when teaching specific subjects such as: Mathematics, Portuguese Language, Chemistry, History, Geography, Physics, Sociology, Philosophy, Art, Portuguese Language, Physical Education and Biology, to the final years of elementary or high school. The objective, therefore, sought through this research was to Develop and apply a training course, given to Basic Education teachers, with the theme Autism Spectrum Disorder, in order to investigate the impact of a course of this nature on the accuracy in adapting theoretical evaluations. In addition to the investigation, the objective was also to discuss and instruct teachers in adapting materials and assessments to be applied in the future to students with autism, according to the assumptions of historical cultural theory and based on the references of the book Modyfing Schoolwork.

\section{Vygotsky and the Possibilities for Thinking about Special Education}

Soviet psychologist Lev Semiónovich Vygotsky has a theoretical trajectory recognized for his ideological and theoretical struggle, for the creations of "defect" psychology and a dialectical materialistic science about the "abnormal and difficult" child. He was concerned with changing the form of understanding the disability, bringing about a release from the biologizing and limiting bias $(\mathrm{Vy}-$ gotsky, 1997). The Vygotskyan work, the central theme of most of his early investigations, is recognized for being the theoretical basis for the development of the human psyche and it was possible to anchor this research based on human defectology. The term that today would easily be criticized for its prejudiced connotation, at the time was used to refer to the study of children with some type of disability, at that time called "defect", which may be physical or mental, also called of intellectual. While we are talking about Vygotsky's studies, we will make use of the words contained in his works, as a defect, for example, having seen that we have clarified the context in which it was mentioned and as a way to recognize its authorship and contributions to the studies of Special Education. The author portrays the definition of defectology in his book History of the Development of Higher Psychic Functions as being "[...] a sphere of theoretical knowledge and scientific-practical work that refers to the child whose development is compromised on the occasion of a defect" (Vygotsky, 1997: p. 3, translation by the author).

In 1924 he published his first writings on defectology, at which time he devoted himself simultaneously to scientific investigations at the Institute of Psychology and to work at the City Commission for Public Education (CPIP), in the 
subsection of education for children with disabilities. The theory of psychic development, developed by Vygotsky when studying the normal child, became the basis for abnormal investigations in childhood. The scientist found that the general laws of child development are also observed in the development of abnormal children (Vygotsky, 1997). By establishing the unity of the psychological regularities of normal children and those suffering from developmental disorders, he was able to substantiate the general idea about the development of the child's abnormal personality.

This study bases what can be considered the first vagueness of the perception of the intrinsic relationship between the biological and neurological aspects of the child, based on the area of health and the practice of Special Education. Vygotsky (1997) proves his conviction in the correlation between areas through his activities related to teaching, in the city of Gomel, in Belarus, where he worked giving courses for teachers, dedicating his full attention to the challenges of teaching children with backwardness mental.

In this sense, we realize the need for a great creative work to restructure our school based on new principles. A discussion that started more than 90 years ago, can be classified as contemporary as we perceive to point in the direction of the need to sketch the basic lines to decide more precisely the starting points for this work.

Currently, it is discussed about the inclusive processes that are responsible for the insertion of students with physical or intellectual impairment in common teaching classes, with or without the presence of a support teacher. This paradigm shift regarding inclusion is due to the analysis that, in spite of all its merits, the Special Education school or, later, the classrooms specifically designed for the Special Education target audience, stood out for a fundamental deficiency: to end the student in a limited circle of school collectivity, creating an isolated and closed micro-world, where everything is adapted and accommodated to the student's deficiency, everything is centered on his insufficiency which prevents him from experiencing authentic, real life. These environments, instead of drawing students from an isolated world, used to develop habits that lead to greater isolation and accentuate separatism (Vygotsky, 1997).

We are facing an excellent opportunity to realize that any type of disability causes social displacement, that is, their social relations are impacted due to their syndromic condition. This happens from the first days of life, at a young age, from the moment when the disability is perceived, the child even acquires a special social position within the family and his relations with the world around him begin to flow from different way from normal children's lives. It also happens that the activities performed by her are diametrically impacted due to the social and cultural contexts in which she is inserted, in this way, the environment is a decisive factor in the direction of her behaviors, as well as her purpose and objectives. The path of the object to the child and from the latter to the object is mediated by the other. At this moment, there is a deep and necessary understanding that the complexity of human structures is an effect of the develop- 
ment process rooted in the links between individual history and social history (Vygotsky, 1997).

Based on this social analysis of the child, Vygotsky warns of an important point about the view of the teacher who is faced with a student with a disability, inviting him to go through the mere physical or mental aspects of the problem, but look at the situation beyond its nuances educational as well as social ones. An example of this is that when we are facing a special education student, we are invited to look beyond the disability itself and its specificities. It is necessary to understand his conflicts in contact with ordinary life, the challenges that limitation imposes on him, his weaknesses and potential. The singularity of the development of the person with a disability lies in the positive effects of the disability and the ways found to overcome it (Vygotsky, 1997).

Based on these assumptions, it is possible to reflect on the place that Special Education occupies within the general education system, if we base ourselves on its thesis that discusses education. After all, all education requires, in the end, to establish some new forms of behavior, to form conditioned reactions or conditioned reflexes, as physiologists say. The challenge that arises is to know the degree of commitment of the channels that connect it to the outside world, recognizing that it is a non-existent or compromised path, but that it can be compensated in other ways.

Vygotsky (1997) asserts that as important as knowing and evidencing the essential theses of special pedagogy, it is to clarify, through scientific thinking, some basic laws of general pedagogy, as the methods developed in the practices of the special school not only benefit children with special needs. syndromic conditions, but also have the potential to generate meaning on the classroom floor of a regular school.

Just as it is possible, but imprudent, to build a house in the sand, one should not build a theory and an educational system based only on good wishes. What he called on the occasion of "The new pedagogy of the disabled child" (Vygotsky, 1997) requires, first, a bold and determined rejection of the entire old system and, second, a rigorous, lucid and consistent commitment to real tasks of the social education of that child, with a view to a late revolutionary reform of the systems that educate children with disabilities "[...] properly organized learning results in mental development and sets in motion various learning processes that would otherwise, would be impossible to happen" (Vygotsky, 1997).

In the light of defectology, children with disabilities are no less developed than those with typical development, but they are children who develop differently. Therefore, being different, children with physical and mental disorders should not be measured with the same standard as the one usually used with the others, because if their reality differs from the others, the managements we will be dealing with must be treated with divergence. Each situation, proceeding in a and unique way (Vygotsky, 1997). 
More than 90 years ago, Vygotsky communicated that there will be a point where each elementary school teacher, which currently implies expanding to all levels of education, will also teach all students, with any type of disability, disorder or syndrome, and therefore, that each regular school consequently becomes an institution capable of promoting education for all (Vygotsky, 1997).

The pedagogy used with students with intellectual problems and global development disorders is at the top of the list of the most undefined and difficult ways to teach. This is due to two factors: there are not yet sufficient, clear, and definitive scientific criteria to support all the specificities of existing nosological entities and due to the variability of characteristics and symptoms existing in Autistic Spectrum Disorder. In the field of neurological sciences, the information and data about the Disorder on screen are still incipient, since it is, as mentioned above, a pathology in which the greatest number of studies and research took place only from the 1950 s onwards.

In this sense, intellectual problems are undoubtedly a concept that embraces a fundamentally heterogeneous group of people, in such a way that we find in the classroom, in most situations, students with the preserved physical aspect, but people with pathological delays present in the spectrum ranging from mild to severe.

This difficulty can be seen in the learning of students with ASD, where the best way of learning is visual capture, and this is enhanced when the teacher makes use of concrete devices (Teixeira, 2016). In this Vygotsky also has contributions, for assuring since the beginning of the twentieth century that "the practical activity with objects allows the development of a basis for the more elaborate thoughts or more complex forms of logical thinking to happen later and become effective" (Vygotsky, 1997).

A precious clue that teachers receive from Vygotsky regarding the way of thinking about their pedagogical practice, concerns the overcoming of the qualitative aspects of the evolution, of the progress and development of the students at the expense of the quantitative ones; that are possible to achieve as long as there is a specially organized planning for this purpose (Vygotsky, 1997). This information gives rise to a broader and more flexible understanding of how to conduct the classes, specifically how the content will be presented and even the possible learning verifiers used in these cases, which may or may not be different in view of the particularity of each student present in the spectrum.

\section{Mathematical Education Inserted in the Context of Special Education}

One of the most significant challenges that the teacher has is the articulation of the theoretical content with the students' everyday reality, so that they can develop better from this interaction (Imbernóm, 2009). This development is assured or, at least, favored when the school recognizes its inseparable connection with society and the professional environment. In this context, being the teacher 
an important agent of change, he has the opportunity to actively participate in the student's potential for improvement, promoting the discovery of personal, cultural and professional identities, contributing to the development of more capable, dignified and respected people in their pluralities.

Thinking about respect for pluralities in a school sphere, brings us to the processes of inclusion of students with special educational needs in common teaching rooms. This is because the proposal of inclusive education imposes a new look at the classroom, a look directed at the performance of this teacher, the formation of this professional, and, at the time of the object of this research, namely a look at the teaching of Mathematics. The choice for the area of knowledge is due to three reasons: first due to the fact that it is historically recognized for its complexity, second due to the scope of the component's learning by students with autism, which can present itself as an obstacle for them due to the requirement of abstract thinking be a prerequisite for understanding some mathematical concepts and third for the incipience of materials that guide generalist teachers on when and how to adapt activities to students with autism inserted in common teaching classes without the presence of a specialist teacher ( $\mathrm{Ma}$ ranhão, 2008).

With regard to Mathematics Education, it is a field of knowledge that although-as a branch of mathematics - has recently emerged, it is an "embryonic discipline" that has been constituted since the beginning of the 20th century, including studies sponsored by UNESCO since 1973, in a context of addressing current trends in science education (Floriani, 2000).

Its genesis is based on mathematics itself, based on its assumptions, but with a look turned to social realities, aiming to contextualize its concepts from the students' experiences. Liell (2017) informs that this branch has been dedicated to the processes related to the teaching/learning of the component and is not limited to "just studying ways of making students reach previously established knowledge, but also problematizing and reflecting on their own mathematical knowledge" (p. 23).

One of the challenges of the mathematical educator is to assume the component's potential as a cultural amplifier of skills, as it is recognized as a people's cultural practice. Still in the calculation of the goals and possibilities of the professional engaged in this theme, there is a dichotomy among the objectives of this field: focus on schooling versus focus on the production of scientific knowledge. Balance is a sine qua non condition for the analyzes that these teachers carry out in terms of "the requirements for knowledge of language, symbolism, mathematical skills and techniques and the requirements of the teaching process in the context of the learner (Floriani, 2000: p. 32).

Contributing to this discussion, Floriani (2000) states that Mathematics Education "is characterized as a praxis that involves the mastery of specific content-Mathematics and the mastery of pedagogical ideas and processes related to the transmission/assimilation and/or appropriation/construction of school ma- 
thematical knowledge".

The urgency of a reflective teacher is evident as it is a branch of mathematics that allows the professional to change his practice, re-signify his performance in the classroom, with a view to promoting a more concrete teaching and with meanings practical. The classroom, as a multiple and heterogeneous context, presents to the teacher today needs to look at the student in its entirety, considering and respecting individualities and human diversity. It is the attribute of this professional to promote that all students, without exception, can access the curriculum and learn.

Depending on this finding, the movement for Mathematics Education from the perspective of Inclusive Education emerged. According to Viana and Manrique (2019), the first vaguest regarding the approach was consolidated only after the Law of Directives and Bases of National Education in 1996. It was "a scope of research linked to mathematical education, but which is constituted with the specificity of enabling the standardization of elements-here the elements that constitute the regular curriculum-for students who present different specificities" (p. 659). Over time, this concept has been improved, starting to see the student from his needs, but with a view to his potential, leaving the bias enabling access to a specific group of students, to become a broad view of the educational context Brazilian, characterized by the diversity of its agents (Viana \& Manrique, 2019).

We assume at that moment the importance of the teacher discussing methodologies and theories of teaching and learning, as well as being an apprentice and overcoming the view of normality historically sustained around a classroom, replacing it with the view of human diversity. In addition to overcoming visions and admitting this importance, the teacher must be prepared to act in contexts of multiple educational needs.

According to Maranhão (2008), it is necessary to defend the continuing education of teachers in Mathematics Education, as it recognizes that Mathematics education focused on contextualization is part of the professional activity of the teacher. He adds that teachers who teach mathematics and who have students with special educational needs in their classroom, need to be prepared.

The experience in the common classroom shows us that it is a challenge when we face students targeting Special Education, especially in Mathematics Education. It is a component that comes loaded with meanings, which brings with it the stigma that not everyone is able to learn it in the same proposal of being extremely necessary for our present and future life, making up the formation of any intelligent, critical and active citizen. It is also important to emphasize that the academic training of teachers in this area, being fundamentally content and overly concerned with algorithms, in many cases, does not include a curricular matrix that favors components that prepare future teachers to work in the perspective of inclusive education (Maranhão, 2008).

As stated earlier, we cannot belittle the urgency of the content framework that 
it receives in its initial training, nor can it refute that the teacher is in a constant learning movement. The proposal is to ratify that the teacher, in addition to solid knowledge in Mathematics, needs to know students well, with or without special educational needs, in their diversity, as well as their diverse contexts of performance, as inclusion does not apply only a portion of the class; your job requires you to be prepared to teach all students, without restrictions.

The much desired and necessary changes in the school and especially in the classroom will occur with the involvement of the teacher, the real agent of change. An effort must be made to overcome the shallow thinking that students targeting Special Education are the responsibility of the specialist educational service teacher or specialist. Brito and Costa (2018) affirm that the act of including needs to be understood no longer as a state, but as a social process with an uninterrupted trajectory, an action that begins within the educational institution, but goes beyond the walls of the school and that, at the ceasing to be purely a goal, becomes a collective and firm commitment.

Our hope is that in the future, it will not be necessary to attribute the perspective of Inclusive Education to Mathematics Education, but that in its entirety, it contemplates in its core human diversity as "an essential element for any and all theoretical and praxeological discussions, being explicitly unnecessary your inclusive perspective" (Viana \& Manrique, 2019).

The success of inclusive practices depends on many variables, but it goes hand in hand with the knowledge of teachers and the use of the most effective curricula and teaching methods. The processes of planning, conducting classes and evaluating the instructions demand that the teams responsible for teaching select and combine ideas that not only translate consistent with current knowledge, but are also practical and efficient in a context of multiple student profiles (Janney \& Snell, 2013). We chose the work Modyfing Schoolwork to compose the theoretical framework of our project as it is a resource that works in practical spheres and that can be used by teams of generalist and specialist teachers and support teams that share the goal of teaching students the target audience of Education Special, especially with Autism Spectrum Disorder.

The solidity of the teaching practices described by the authors is based on research and solid evidence, validated in context settings with the presence of mixed skills, and promising as inclusive practices due to their flexibility and responsiveness to students' individual differences. Its line of approach and strategies were influenced by the research of educators and scholars, as well as its conceptual questions, extracted and adapted from the publications of specialists whose research and writing for years have guided the practice of inclusive education. They are master teachers with years of experience teaching students with diverse needs and skills and recognized for having designed much of the students' specific planning techniques and practical examples of strategies of adaptation contained in the work (Janney\& Snell, 2013).

The authors also inform that in addition to suggesting the goals for Individua- 
lized Educational Programs, it offers the services and support necessary to achieve them and ensures that "although some of the strategies offered by the book are presented as ideal, readers can be sure they come from real teachers in real classrooms, where each school day brings challenges and rewards" (Janney \& Snell, 2013: p.12).

According to Janney and Snell (2013) when writing about changes in school work from the perspective of inclusive education, they aimed to describe and illustrate a flexible and coordinated approach by which educational teams can plan and provide effective instructions to students with diverse skills and create more specialized support and interventions for students who need them, taking care not to damage their sense of belonging or status as students.

His studies focus on the process of developing guidelines for adapting materials and activities according to universally possible instructions, as well as incorporating support for specific students, to meet their individual educational needs, while maintaining their participation in the classroom.

As mentioned above, its focus is specific strategies for use by members of the school team who design daily instructions for use in the classroom. The richness of its construct lies in the fact that throughout the work, each planning strategy is illustrated with examples of cases extracted from classrooms and students known to the authors, in addition to offering in their Appendices, blank copies of these forms.

In our country, according to the Law of Directives and Bases of Education, in Article 58 of Chapter V, Special Education is defined as the "Modality of school education offered preferably in the regular school system, for students with disabilities, global development disorders and high skills or giftedness" (Brasil, 1996). For Janney and Snell (2013), translation by the author), "inclusion is much more than a place and much more than an effort to change the services and strategies of Special Education". Despite the fact that the official documents contemplate the concept of Special Education, as in our country, the authors warn that the definition does not refer to the place where these instructions occur, nor does it guide how to adapt, what to adapt and who should do it. Thus, the work was chosen for basing its practices on collaborative problem-solving processes and guiding the decision-making involved in answering these questions.

\section{Methodological Proposal}

In line with the nature of the data produced by the research, as well as recognizing the complexities of the theme itself and of the school, the environment in which it is inserted, it was decided to search for quantitative and qualitative approaches. The first approach is justified because of the need to translate the information contained in the assessments adapted by the teachers at the end of the training course into numbers, as opposed to the assessment aimed at students with typical development, in the urgency of classifying and analyzing them 
(Kauark, Morhães, \& Medeiros, 2010). And the choice for the qualitative approach, as it provides the intrinsic relationship between theory and practice and in function of that it will be able to offer the necessary subsidies with the rigor required in conducting the theme. How the source of data collection is found in the natural environment; the data from this collection is predominantly descriptive; these are analyzed inductively, with the meaning of greatest importance and, finally, the greatest concern of qualitative researchers lies in the process, and not the product (Bogdan \& Biklen, 1994).

The research was applied in a private school that currently has students regularly enrolled in Early Childhood Education, Elementary School I, II, and High School. The subjects of this research are 24 teachers working in Early Childhood Education, Elementary and High School, together with the management team composed of the general director and the two pedagogical coordinators, totaling 27 teachers.

For that, a mathematical evaluation formulated by the researcher was used as a data collection instrument, in which the teachers carried out the adaptation minutes before the course, as a way of evaluating their personal repertoire and immediately at the end of the course, with the information received, received the same blank evaluation again so that they could adapt. The research subjects received, together with the evaluation, a document called "Description of the Student Profile" to which the adaptation was carried out. This record refers to the creation by the researcher of a model student with autism, with a particular profile, and its objective was to present the teacher with the name, age, grade, curriculum component contained in the assessment, that student's diagnosis, comorbidities and your hyper-focus. The document also contained data such as the student's repertoire, his skills, and the skills he already has in Mathematics. As the adaptation process is completely personalized, based on outlining individualized intervention and teaching objectives, teachers need to receive a complete description of that student.

The research stages consist of preparing the training course, conducting the course, and analyzing the assessments carried out before and after the course. Once the training was completed, the content analysis was systematized, from the detailed reading and exploration of the questions recorded in the evaluations, culminating in a presentation of the results, through analysis categories described by Janney and Snell (2013). This research was submitted to "Plataforma Brasil" and underwent an evaluation by the Ethics Committee for Research on Human Beings (CEPH), and approval was granted through opinion number 26002619.5 .0000 .5370 .

\section{Results and Discussion}

Content Analysis was the chosen method for interpreting the data collected, specifically through the organization into categories, with input from the material extracted from the evaluations, carried out by the teachers before and after 
the training course. In this research, we start from the categories created posteriori. According to Bardin (1977), this modality is defined by the researcher when he chooses to collect in the material the discourses that arise from the data derived from the results, in addition to their immediate meanings.

The data obtained through pre-tests and post-tests are presented in the next section, in the form of categories, and analyzed in the light of the theories that discuss the theme of this research. In this way, through an examination guided by the indicators, the researcher has possibilities of discussions more in line with the proposed objectives, minimizing the risks of suffering damage in the objectivity of the investigation.

CATEGORY 1: UNDERSTANDING THE CONTEXT IN WHICH STUDENTS ARE INSERTED

Pondering the aspects of the student's personality as a person with autism makes it possible to work on their potential, but implies knowing them, recognizing the themes and/or objects of their greatest interest. The DSM- V informs that "the diagnosis of autism spectrum disorder requires the presence of restricted and repetitive patterns of behavior, interests or activities".

Attachment to a specific theme is capable of generating benefits to the subject in the classroom, that is, the teacher has the opportunity to give functionality to that subject of his fixed interest, and to take advantage of it in the process of its full development, serving for the experience of this individual (Kuntz, Santos, \& Kennedy, 2020). This intense form of concentration on the same theme or object, present in people with autism, is called hyper-focus and can be used by teachers in the acquisition of new skills, being potentially recognized for the possibility of learning to take place according to their experiences. and, therefore, be full of meanings.

The "Student Profile Description - Model" (Figure 1) in our continuing education course suggests the presence of farm animals as a hyper-focus. This aspect is consistent with the urgency of the teachers when adapting the statements of the assessments, considering this aspect of the student, and verifying if they understood the context in which the student is inserted. In this way, the results of the teachers' performance about this criterion will be presented below. It is worth noting that the data recorded in the table represent the number of teachers who included farm animals in the statement of questions.

Through Table 1 records the percentage data, we can assert that the continuing education course was sufficient to generate in the participating teachers the accuracy in adapting the proposed activities. It is worth mentioning that none of the values reached $100 \%$, but the expressive and favorable increase between the results in the pre and post tests, suggest that when learning about the positive effect and how to use the restricted interests in the educational context, teachers are able to perform that level of adaptation.

CATEGORY 2: ARTICULATION OF KNOWLEDGE, PROMOTING THE UNION BETWEEN THEORY AND PRACTICE 
According to Janney and Snell (2013) inclusive education requires that teachers have 1) a solid conceptual understanding of groups of students with widely different characteristics and skills and their deficiencies; and 2) knowledge and skills to implement specific ways to promote student learning. In this complex context of innovation, one of the great challenges that is imposed on teachers in the classroom is the articulation between what we learn in continuing education courses and the ways of structural innovation and in teaching, that is, making individualized adaptations. This is all packed with the greatest sense of urgency as possible, as each year the number of enrollments of students targeted by Special Education in common teaching classes is higher.

Table 1. Adaptation of the Statements based on the Criterion.

\begin{tabular}{|c|c|c|c|}
\hline \multirow{2}{*}{ QUESTION } & PRE TESES & POST TESES & \multirow{2}{*}{$\begin{array}{l}\text { PERCENTAGE } \\
\text { INCREASE (\%) }\end{array}$} \\
\hline & SUCCESS RATE (\%) & SUCCESS RATE (\%) & \\
\hline 3 & 18.5 & 66.6 & 48.1 \\
\hline 4 & 25.9 & 77.7 & 51.8 \\
\hline 5 & 7.4 & 55.5 & 48.1 \\
\hline 6 & 22.2 & 37.03 & 14.8 \\
\hline 7 & 29.6 & 70.3 & 40.7 \\
\hline 8 & 18.5 & 48.1 & 29.6 \\
\hline 9 & 33.3 & 81.4 & 48.1 \\
\hline
\end{tabular}

Source: prepared by the researcher.

Name: João Alexandre Retzlaff
Sge: 10 years
Series: Fifth grade of elementary school
Subject: Mathematics
Diagnosis: Autism Spectrum Disorder - Level 1
Comorbidity: TDHA
Hyper-focus: farm animals
1) Carry out activities more slowly, so as not to be able to complete all questions within the standard time allotted for evaluation.
2) Has difficulty memorizing mathematical symbols and formulas.
3) Has compromise in memorizing the multiplication tables. Especially in the tables of $6,7,8$ and 9 .
4) It presents difficulty in memorizing the units of measurement of length.
5) Reads and writes units well, tens and hundreds. It presents difficulty in discriminating the units, tens, and hundreds of thousands. The rest have not yet
mastered.
6) Has difficulties with complex texts.
7) Can add, subtract, multiply and divide units, tens, and hundreds. And it is difficult to quantify the units, tens, and hundreds of thousands.
8) Hyper focus on farm animals.
9) It presents difficulties with abstraction, being the visual its best way of capturing learning.
10) It presents difficulties in the attention and discrimination of the central aspects for the comprehension of the text.
11) Has difficulties with large texts.

Figure 1. Description of student profile-model. 
The data generated by the analysis of the evaluations carried out before and after the continuing education course were compiled and expressed in the following Table 2.

The intervention demonstrated a considerable increase in the accuracy of teachers in adapting the statements of the questions of a theoretical evaluation for a student with autism. The current scenario of Special Education presents peculiarities that demand from teachers a solid theoretical and practical training so that they can understand and practice the profession, as well as achieve teaching competence in different contexts. However, what is observed are academic works in the sphere of Teacher Education from the perspective of Special Education that allude to the concepts of Vygotskian theory, but do not present resources for the application of its principles, transposing the theoretical conception to carry out educational work in itself.

The range of concepts coupled with practical examples of approaches that meet the learning characteristics of students with Autism Spectrum Disorder learned in the training course, contributed so that teachers could articulate theory with practice. The data show that the course taught by the researcher in fact taught general approaches and specific strategies that help educators in a deliberate and proactive way to design instructions that respond to the variability of students present in their classrooms, and the material developed and used during the course. Training represent broad structures that provide guidelines and strategies to make the curriculum accessible to students with the profile according to our model.

Table 2. Crossing of student profile information with adaptations.

\begin{tabular}{|c|c|c|c|c|c|c|}
\hline \multirow[b]{2}{*}{ QUESTION } & \multicolumn{2}{|c|}{ PRE TESES } & \multirow[b]{2}{*}{$\begin{array}{l}\text { SUCCESS } \\
\text { RATE (\%) }\end{array}$} & \multicolumn{2}{|c|}{ POST TESES } & \multirow[b]{2}{*}{$\begin{array}{l}\text { SUCCESS } \\
\text { RATE (\%) }\end{array}$} \\
\hline & PERFORMED & $\begin{array}{c}\text { NOT } \\
\text { PERFORMED }\end{array}$ & & PERFORMED & $\begin{array}{c}\text { NOT } \\
\text { PERFORMED }\end{array}$ & \\
\hline 1 & 14 & 13 & 51.8 & 25 & 2 & 92.5 \\
\hline 2 & 4 & 23 & 14.8 & 10 & 17 & 37.03 \\
\hline 3 & 4 & 23 & 14.8 & 11 & 16 & 40.7 \\
\hline 4 & 8 & 19 & 29.6 & 23 & 4 & 85.1 \\
\hline 5 & 5 & 22 & 18.5 & 19 & 8 & 70.3 \\
\hline 6 & 4 & 23 & 14.8 & 8 & 19 & 29.6 \\
\hline 7 & 4 & 23 & 14.8 & 10 & 17 & 37.03 \\
\hline 8 & 2 & 25 & 7.4 & 6 & 21 & 22.2 \\
\hline 9 & 12 & 15 & 44.4 & 22 & 5 & 81.4 \\
\hline 10 & 1 & 26 & 3.7 & 12 & 15 & 44.4 \\
\hline
\end{tabular}

Source: prepared by the researcher.

CATEGORY 3: BUILDING NEW KNOWLEDGE ABOUT TEACHING SKILLS

The category on screen was created to enable us to present and discuss quantitatively the data referring to the survey of the percentage values of correct an- 
swers in the adaptations of each command of the questions of the theoretical evaluation. We compiled the information in Table 3 and immediately afterwards we presented graphs that facilitate the presentation and interpretation of the values.

Our concern in analyzing these data lies in knowing that, according to Vygotsky (1997), the practice of wrong educational actions, fundamentally in the field of Special Education, compromises and restricts the students' learning possibilities.

It is necessary to talk about the values themselves and the distance of some averages, registered in the tables mentioned above, of the so desired $100 \%$ that represent the totality of correctness on the part of the research subjects. If the mental and psychological development is directly proportional to the learning as the internalization of concepts gradually occurs, and that all these steps make up a process, we can infer that one of the factors that makes the score distant from $100 \%$, is the short time offered between training and verification of learning through the post-test. We imagine that if at the end of the course, before the post-tests, there was an opportunity to jointly discuss the theme, by way of example, the teachers' experiences with students with ASD, we could improve the rates. In this way, we agreed with Vygotsky (1997) on the importance that refers to the social plane, capable of determining the quality of development and pedagogical intervention interfering with knowledge.

Table 3. Percentage representation of adaptation of assessment statements.

\begin{tabular}{|c|c|c|c|}
\hline \multirow{2}{*}{ QUESTION } & PRE TESES & POST TESES & \multirow{2}{*}{ INCREASE (\%) } \\
\hline & SUCCESS RATE (\%) & SUCCESS RATE (\%) & \\
\hline 1 & 51.8 & 92.5 & 40.7 \\
\hline 2 & 14.8 & 37.03 & 22.23 \\
\hline 3 & 14.8 & 40.7 & 25.9 \\
\hline 4 & 29.6 & 85.1 & 55.5 \\
\hline 5 & 18.5 & 70.3 & 51.8 \\
\hline 6 & 14.8 & 29.6 & 14.8 \\
\hline 7 & 14.8 & 37.03 & 22.23 \\
\hline 8 & 7.4 & 22.2 & 14.8 \\
\hline 9 & 44.4 & 81.4 & 37 \\
\hline 10 & 3.7 & 44.4 & 40.7 \\
\hline AVERAGE & 21.46 & 54.026 & 32.566 \\
\hline
\end{tabular}

Source: prepared by the researcher.

In spite of not having reached the minimum of $70 \%$ of correct adaptations, we can say that the intervention carried out with the teachers was sufficient to add to the participants' repertoire the strategy of teaching the adaptation of activities, 
because, according to the same tables explained previously, none of the data remained stable, that is, there was a significant increase in the subjects' performance. Thus, demonstrating that continuing education on this theme, defining a student model to whom adaptations will be made, is highly effective in training generalist teachers to adapt activities for students with autism.

\section{Final Considerations}

Inclusion is infinitely more complex than guaranteeing the enrollment of the target public of Special Education in a common school, the provision of supports, structural innovation, teacher training or the adaptation of materials and content. Inclusion refers to renewal and change in mentality and the school environment to meet all demands for learning, whether guided by a report. The success of inclusive practices depends on many factors and passes inextricably through the teachers' knowledge about teaching their component using more effective methods that meet the multiple needs of current educational settings.

This project valued the proposal of continuing education to train teachers on the theme of Autism Spectrum Disorder when building and discussing their categories in the formative context. However, far from our pretensions is the exhaustion of this issue and we humbly assume that we have discussed only one of the possibilities for adaptation. It is an incipient field in research and practices that should be explored, in the perspective that our target students of Special Education are in the classroom more than merely present, but are active participants in social and academic activities with their colleagues.

\section{Conflicts of Interest}

The authors declare no conflicts of interest regarding the publication of this paper.

\section{References}

Bardin, L. (1977). Content Analysis. Lisboa: Edições 70.

Bogdan, R., \& Biklen, S. (1994). Characteristics of Qualitative Research. In Qualitative Research in Education: An Introduction to Theory and Methods (336 p). Porto: Porto Editora.

Brasil (1996). Federal Government Law Guidelines and Bases of National Education. Law No. 9,394, of December 20, 1996. Brasília.

Brasil (2020). National Institute of Educational Studies and Research Anísio Teixeira (Inep). Basic Education Census 2019: Statistical Notes. Brasília.

Brito, F. C., \& Costa, V. B. (2018). Teacher Education in Inclusive School Looks, Perspectives and Different Approaches. Curitiba: CRV.

De Viana, E. A., \& Manrique, A. L. (2019). Mathematical Education in an Inclusive Perspective: Investigating the Conceptions Constituted in Brazil since the 1990s. Perspectives of Mathematical Education, 11, 649-666.

Floriani, J. V. (2000). Professor and Researcher (2nd ed.). Blumenau: Editora da FURB.

Imbernóm, F. (2009). Teacher and Professional Training: Training for Change and Un- 
certainty (7nd ed.). São Paulo: Cortez.

Janney, R., \& Snell, M. (2013). Modifying Schoolwork (3rd ed.). Baltimore, MD: Paul H. Brooks Publishing Co.

Kauark, F., Morhães, F. C., \& Medeiros, C. H. (2010). Research Methodology: Practical Guide. Itabuna: Via Litterarum.

Kuntz, E. M., Santos, A. V., \& Kennedy, C. H. (2020). Functional Analysis and Intervention of Perseverative Speech in Students with High Functioning Autism and Related Neurodevelopmental Disabilities. Journal of Applied Behavior Analysis. https://doi.org/10.1002/jaba.669

Lacerda, L. (2017). Autistic Spectrum Disorder: A Very Brief Introduction. Curitiba: CRV.

Liell, C. C. (2017). A Mathematics and the Interrelationship with Environmental Education. Thesis (Doctorate in Science and Mathematics Teaching), Canoas: Universidade Luterana do Brasil.

Maenner, M. J. et al. (2020). Prevalence of Autism Spectrum Disorder among Children Aged 8 Years-Autism and Developmental Disabilities Monitoring Network, 11 Sites, United States, 2016. MMWR Surveillance Summaries, 69, 1.

Maranhão, M. C. S. de A. (2008). Formative Spaces in a Basic School and Didactic Knowledge about Whole Numbers of Teachers of the Early Years of Elementary School. Mathematical Education Research, São Paulo, 10, 35-50.

Teixeira, G. (2016). Autism Handbook. Rio de Janeiro: Best Seller.

Tibyriçá, F. R., \& D’Antino, F. M. E. (2018). Law of People with Autism: Interdisciplinary Comments on Law 12.764/12. São Paulo: Memnon Scientific Editions.

Vygotsky, L. S. (1997). Obras Escogidas V. Fundamentos de defectologia. Madrid: Centro de Publicaciones Del MEC y Visor Distribuciones. 